CASE REPORT

\title{
Liposuction sepsis - be alert
}

Michael SG Bell MD FRCSC ${ }^{1}$, Geoffrey P Doherty MD MSc FRCPC ${ }^{2}$, Andrea Gutauskas MD³

MSG Bell, GP Doherty, A Gutauskas. Liposuction sepsis - be alert. Can J Plast Surg 2009;17(4):e29-e32.

Postoperative infection in liposuction patients may be exceedingly difficult to clinically appreciate because of the skin edema, colour changes and even blistering that can occur. The authors outline such a case with practical advice about establishing an accurate and precise diagnosis of an early septic process.

Key Words: Liposuction: complications; Liposuction: necrotizing fasciitis; Liposuction: postoperative sepsis

$\mathrm{L}$ iposuction is a frequently performed, minimally invasive procedure with a good safety record, but as with any operation the complication rate is not zero (1).

An acute life-threatening septic process after liposuction is exceedingly rare, and there are few references in the literature to remind us of this reality $(2,3)$. The authors report such a case.

\section{CASE PRESENTATION}

A 58-year-old woman in good health, with stable weight and a body mass index of $26 \mathrm{~kg} / \mathrm{m}^{2}$, presented with local fat deposition on her central abdomen, in the lateral thigh areas over an area $22 \mathrm{~cm} \times 15 \mathrm{~cm}$ and on her upper medial thighs in an area approximately $12 \mathrm{~cm} \times 10 \mathrm{~cm}$ in size. She had good-quality skin and was considered a reasonable candidate for liposuction.

This procedure was done in a fully equipped office setting. Intravenous sedation was administered, and the five areas were infiltrated with a total volume of $3 \mathrm{~L}$ of tumescent solution.

Liposuction was carried out with a combination of $3.6 \mathrm{~mm}$ and $3 \mathrm{~mm}$ cannulas; a total volume of $1500 \mathrm{~mL}$ was removed, of which $900 \mathrm{~mL}$ was visible fat. The incisions were sutured.

The entire procedure was uneventful. It took approximately $1.5 \mathrm{~h}$, and the patient left for home feeling well approximately $3 \mathrm{~h}$ after the procedure began.

At $24 \mathrm{~h}$ she phoned and indicated that she was having significant abdominal pain that had seemingly gotten worse over the preceding $6 \mathrm{~h}$ and had not been relieved by acetominophen and codeine $(300 \mathrm{mg} / 30 \mathrm{mg})$.

It had been observed at the time of surgery that she seemed unduly sensitive to the discomfort of starting an intravenous line and the freezing procedure with the tumescent solution, and it was thought that upgrading her prescription to Percocet (Bristol-Myers Squibb Canada) might be effective.

She was telephoned $4 \mathrm{~h}$ after that, and she reported that there had been some relief with the new medication and that she was much more comfortable.

Three hours after that ( $30 \mathrm{~h}$ postoperative liposuction) she telephoned to report the development of some early superficial

\section{Se méfier de l'infection post-liposuccion}

\begin{abstract}
L'infection post-opératoire chez les patients soumis à une liposuccion peut être extrêmement difficile à évaluer sur le plan clinique en raison de la présence d'œdème cutané, d'altération de la couleur de la peau et parfois même de vésicules. Les auteurs en décrivent ici un cas et formulent quelques conseils pratiques pour l'établissement du diagnostic juste et précis dès le début du processus infectieux.
\end{abstract}

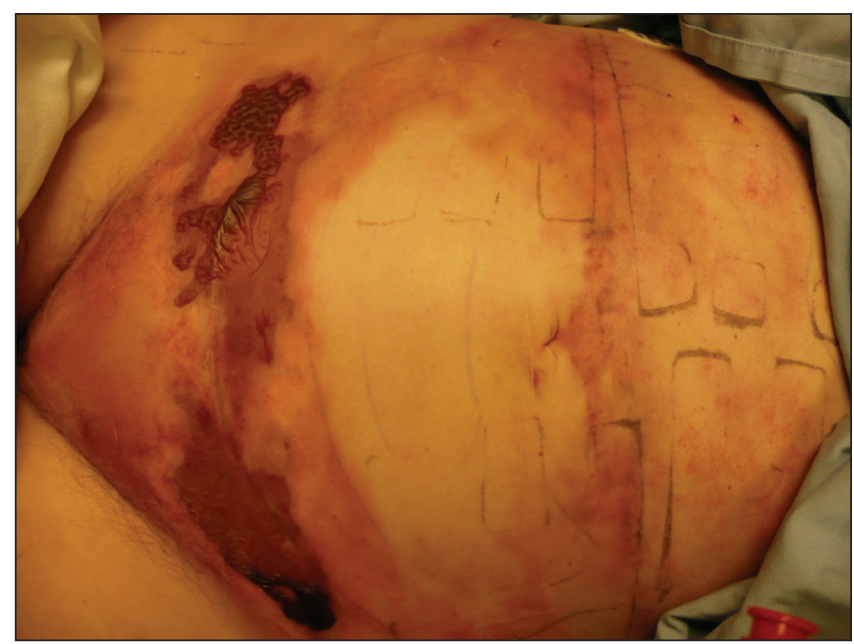

Figure 1) Photograph at time of presentation with blistering along the old Pfannenstiel incision (October 12, 2007)

dark coloured 'blood blisters' in the area of an old Pfannenstiel incision on the lower abdomen. Her pain seemed worse again. She was told to come immediately to the hospital.

On arrival at the hospital she was slightly nauseated, and did vomit on one occasion. She reported having chills, although she was afebrile.

The major alarming feature was hypotension measured at 70/40 mmHg. Her mentation seemed normal and she had complaints of localized periumbilical pain.

She was immediately given $2 \mathrm{~L}$ of fluid over the space of an hour, but her blood pressure did not rise.

The appearance of the blisters was an ominous sight, coupled with marked skin hypersensitivity (Figure 1). A general surgical consultation was obtained.

Because of the known potential of perforation of a viscus with liposuction and the localized abdominal pain, the general surgeons wished to have a computed tomography (CT) scan, and this was carried out as promptly as possible. There were detectable areas of air in the subcutaneous tissue, but this was

${ }^{1}$ The Department of Surgery, Division of Plastic Surgery; ${ }^{2}$ Department of Anaesthesia; ${ }^{3}$ The Department of Surgery, Division of General Surgery,

The Ottawa Hospital-Civic Campus, Ottawa, Ontario

Correspondence: Dr Michael SG Bell, 402-1919 Riverside Drive, Ottawa, Ontario K1H 1A2. Telephone 613-739-5424, fax 613-739-7168,

e-mail msgbell@cyberus.ca 

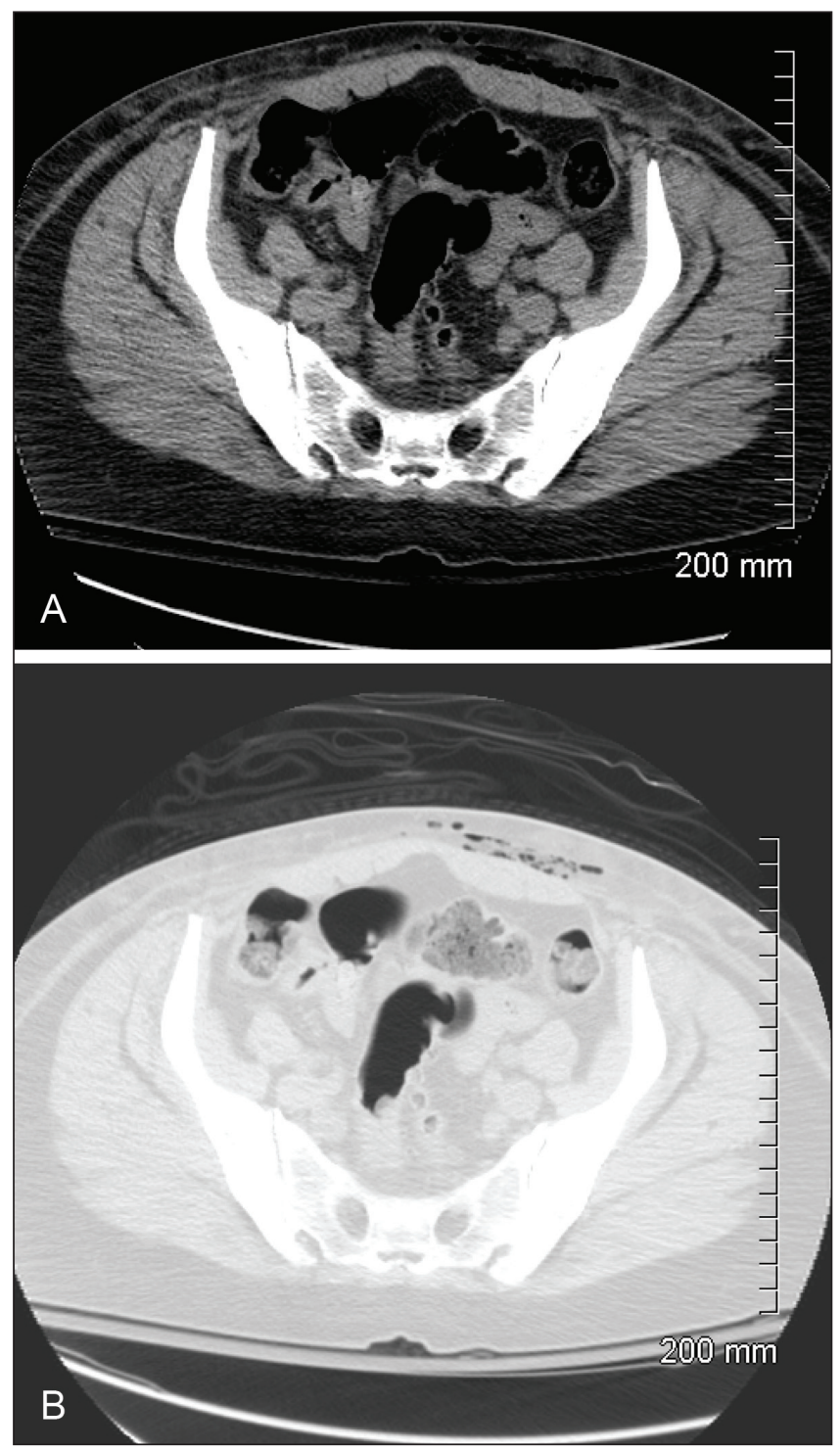

Figure 2) Axial unenhanced computed images of the abdomen ( $k \mathrm{~V}$ $120 \mathrm{kEV}, 5 \mathrm{~mm}$ slice thickness) with abdominal (A) and lung (B) window levels. There are numerous locules of air in the subcutaneous fat of the left anterior abdominal wall. There is no intraperitoneal free fluid or inflammatory changes. There is no fluid collection or abscess in the anterior abdominal wall. The subcutaneous gas is nonspecific and consistent with history of recent liposuction

thought to be compatible with recent local liposuction. This noncontrast CT study also demonstrated that there was no anterior abdominal wall fluid collection or intraperitoneal complication (Figure 2) (4). With this being established, the patient was taken immediately to the operating room for surgical intervention with the diagnosis of necrotizing fasciitis.

She entered the operating room $40 \mathrm{~h}$ after the beginning of her original liposuction procedure. Throughout the course of her operation her blood pressure was unstable, requiring pressor agents. There were discrete areas of skin necrosis underlying the blisters. An area of skin approximately $4 \mathrm{~cm}$ in width was excised transversely across the $20 \mathrm{~cm}$ long Pfannenstiel incision. The fascia appeared healthy, and the process seemed to be more a true hemolytic streptococcal gangrene in terms of appearance. Questionably viable subcutaneous fat was found on the right side as high as the umbilicus and was excised. The skin bled well superficially and it was left.

The patient remained unstable for essentially $24 \mathrm{~h}$ on pressor support. Her white count remained below $5 \times 10^{9} / \mathrm{L}$ the entire time. She did not spike a fever. Her creatinine was elevated at the time of presentation at 168 and lactate was 5.9. A magnetic resonance imaging (MRI) scan was performed $36 \mathrm{~h}$ postdebridement because she had not significantly improved, and demonstrated only thin areas of edema along the superficial fascia of the anterior abdominal wall and in the thighs with no evidence of persistent necrotizing infection (Figure 3) (5).

The wound was serially observed with dressing changes, but the area of skin necrosis did not progress.

A MRI scan was once more performed at $72 \mathrm{~h}$ because of the development of blistering and hemorrhagic changes on the left lateral thigh (Figures 4 and 5), which did not indicate advancing infection. This MRI's imaging findings were similar to that of the first MRI scan performed postoperatively.

The patient progressively began to improve. She did not develop disseminated intravascular coagulation or acute respiratory distress syndrome, although she had a small pleural effusion. She began to diurese on the seventh day.

The wound margins were debrided on the seventh day on her abdomen and left thigh, with good bleeding evident, despite the outward appearance of severe bruising, which was thought preoperatively to be potentially progressive local ischemia.

She required ventilation support for 14 days and was discharged from the intensive care unit on day 18 (Figure 6).

The photographs demonstrate the initial cutaneous signs of this evidently severe rapidly progressive infection which could well have been fatal. Closure was eventually achieved with a combination of dynamic traction aids (Canica Design Inc, Canada) (Figures 7 and 8 [abdomen] and Figures 9 and 10 [thigh]).

The history of disproportionate pain, the hypotension and the early signs of blistering were the only clinical features. A CT scan, which is more easily accessible and more rapidly performed than a MRI examination, was able to eliminate peritoneal perforation as a postoperative complication. The imaging findings of necrotizing fasciitis are soft tissue gas, fluid collection tracking along fascial planes, focal fluid collections/ abscesses, fascial enhancement, and necrosis of fascial planes and muscle (9). CT is more sensitive to soft tissue gas although MRI is better at fascial enhancement and abnormal areas of enhancement. MRI is reported to have a very high sensitivity and high specificity for the detection of necrotizing fasciitis: $89 \%$ to $100 \%$ and $46 \%$ to $86 \%$, respectively $(4,8)$. For this patient, an MRI scan done initially that first night may have been more suggestive; however, when performed the day following debridement it was a useful test in determining that the slow clinical response and continued need for pressors was not on the basis of ongoing spread of infection.

This particular infection would be best categorized as acute streptococcal hemolytic gangrene (6). The only organism grown was group $G$ streptococci (www.uptodate.com for details). Although there was necrotic fat at the level of fascia, the fascia 

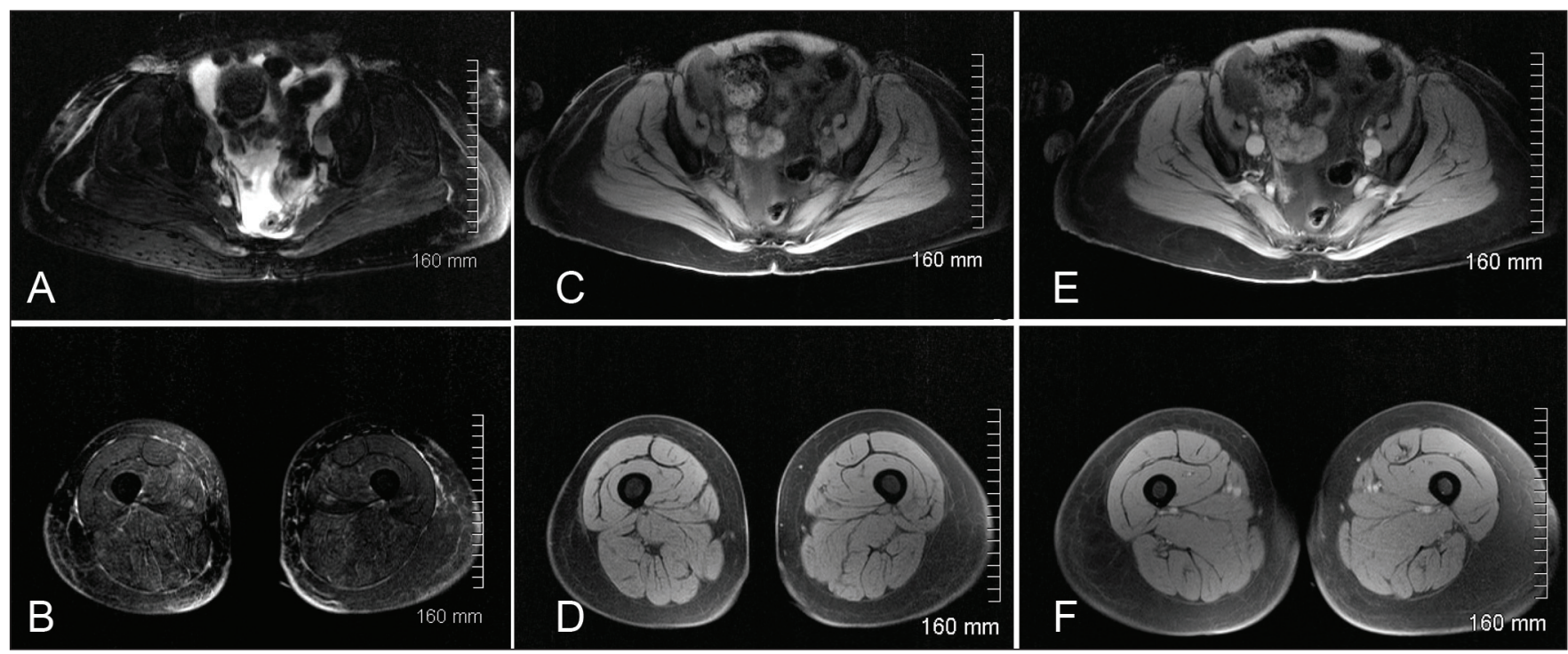

Figure 3) Axial T2-weighted turbo spin-echo (TR 3210, TE 100, NEX 1, FOV 160 mm, matrix 258 × 448, 7 mm slice thickness) (A, B) and axial T1-weighted water excitation (TR 500, TE 5.8, NEX 1, FOV $160 \mathrm{~mm}$, matrix $256 \times 512,7$ mm slice thickness) without (C, D) and with $(\mathrm{E}, \mathrm{F})$ gadolinium enhancement of the abdomen $(\mathrm{A}, \mathrm{C}, \mathrm{E})$ and mid thighs $(\mathrm{B}, \mathrm{D}, \mathrm{F})$. The signal voids in the anterior abdominal wall is packing material following debridement of the necrotic infection. There is increased signal along the right anterior abdominal wall superficial fascia and circumferentially around the superficial fascia of the bilateral thigh. There is no deep fascia edema or fluid in the thighs. There is no fascial enhancement or fluid collection. There is increased signal on the T2-weighted turbo spin-echo images tracking along the superficial fascia of the thighs bilaterally

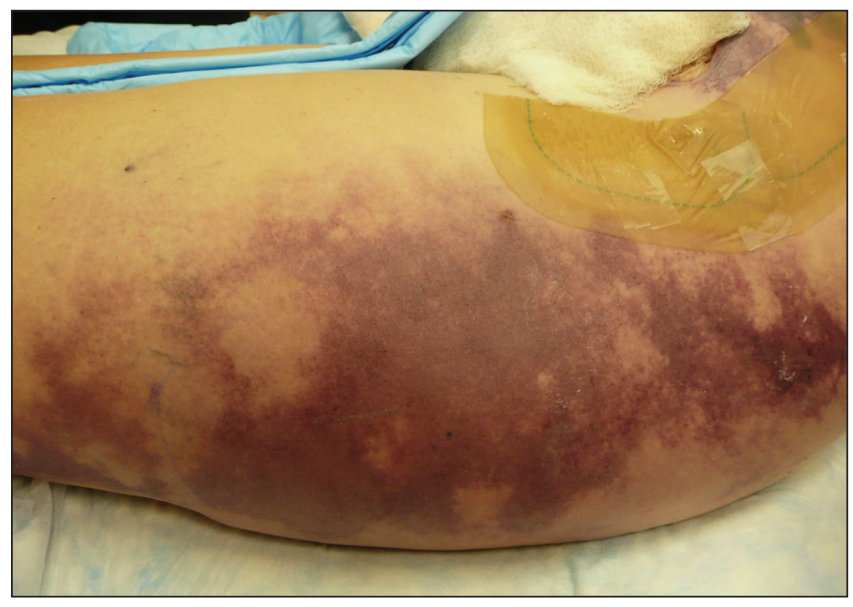

Figure 4) Left thigh, initial presentation in the emergency department (October 14, 2007)

did not yet exhibit the 'necrotic' appearance with the separation of the overlying soft tissues with a sweep of a finger that classically occurs.

\section{DISCUSSION}

The present case report should serve to reinforce our vigilance for unexpected, potentially fatal infections that may be exceedingly difficult to clinically diagnose after minimally invasive surgery or liposuction. MRI scanning done early and repeated if necessary may be the best means of determining progression of the septic process in these severely ill patients. MRI should not delay appropriate aggressive surgical management unnecessarily, and CT examination can be a useful and more expedient alternative imaging test. It is probably academic to try to differentiate between acute hemolytic streptococcal gangrene and

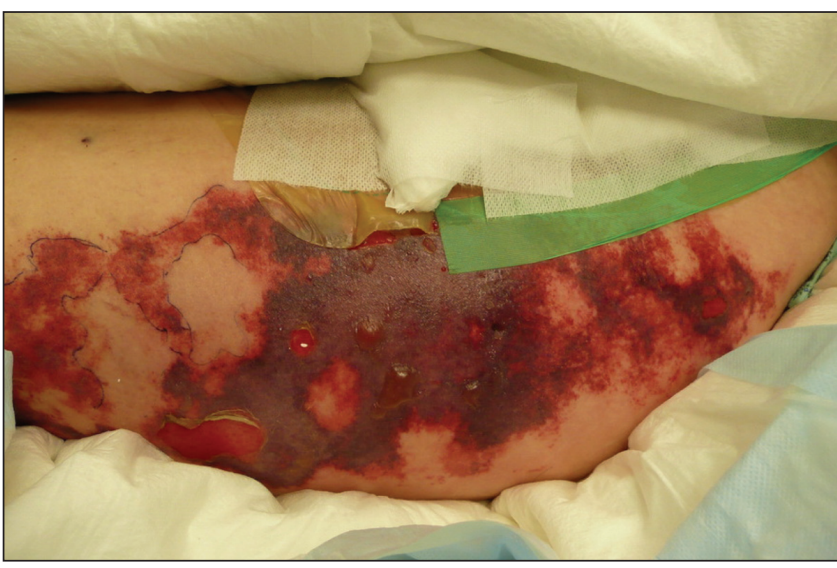

Figure 5) Left thigh three days after presentation to the emergency department (October 17, 2007)

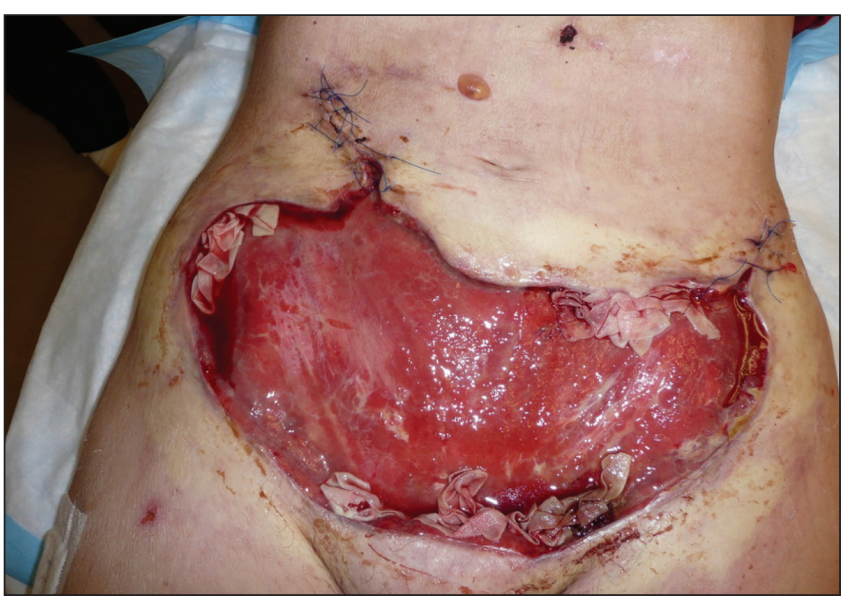

Figure 6) Appearance of the debrided wound at the time of discharge from the intensive care unit (November 5, 2007) 


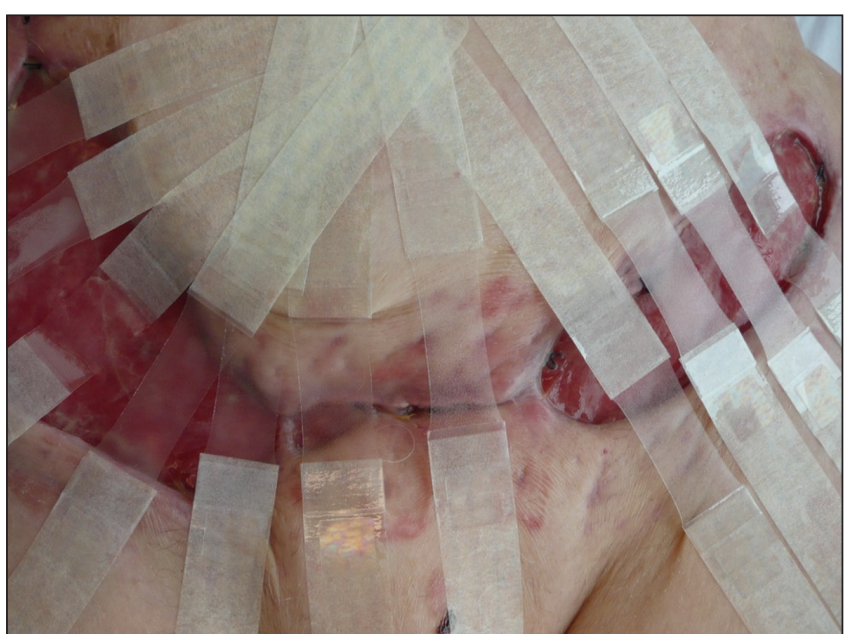

Figure 7) Dynamic skin taping of the abdomimal wound to assist wound closure (December 7, 2007)

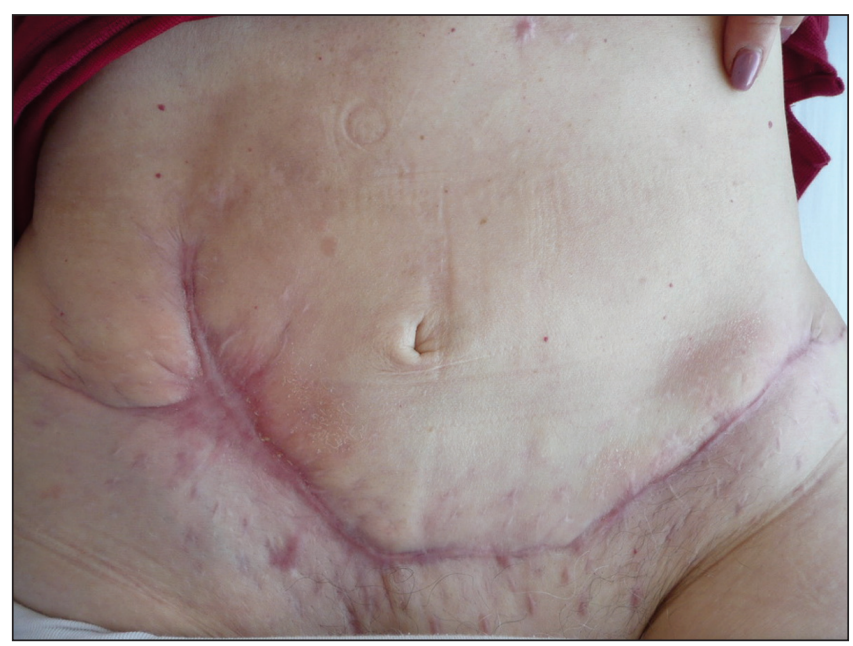

Figure 8) Abdominal wound six months post-sepsis (April 22, 2008)

necrotizing fasciitis. The presentation and course are identical. Urgent debridement is requisite for patient survival and only prompt diagnosis will avoid disaster (10).

This is written to raise the index of suspicion of physicians who may encounter a patient postoperatively from any minimally invasive surgery, to the possibility of an early septic process.

\section{REFERENCES}

1. Peters W. Tumescent liposuction: A plastic surgeon's perspective. Can J Plast Surg 2002;10:75-7.

2. Heitmann C, Czermak C, Germann G. Rapidly fatal necrotizing fasciitis after aesthetic liposuction. Aesth Plast Surg 2000;24:344-7.

3. Brown SL, Bacsanyi JT, Purvis-Wynn SL. Fatal and serious complications associated with cosmetic suction lipectomy. Can J Plast Surg 2002;10:69-74.

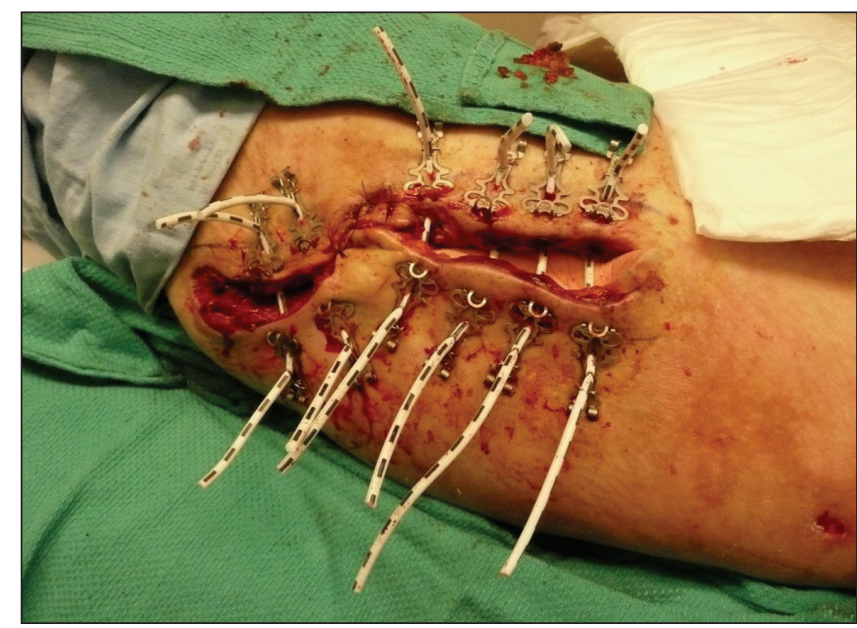

Figure 9) Dynamic closing of the left thigh (November 5, 2007)

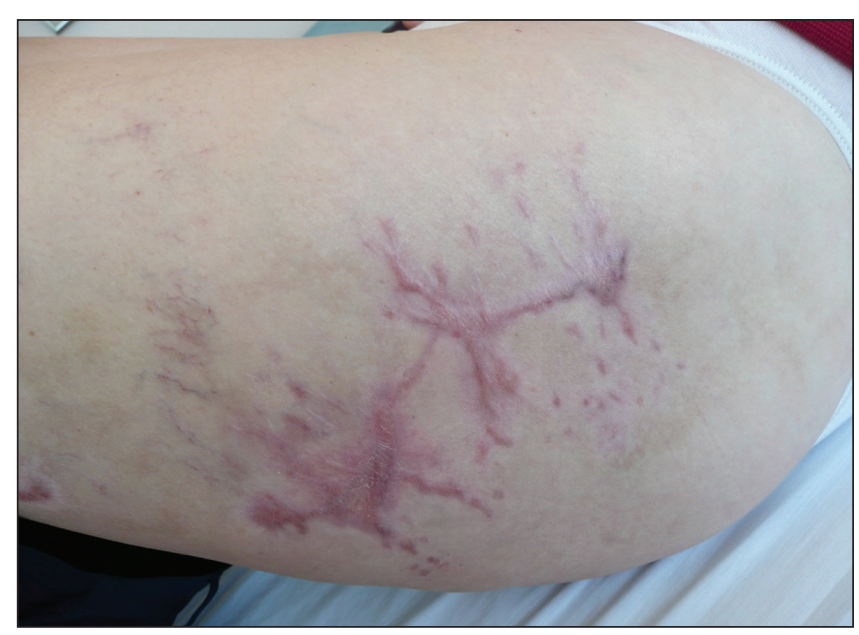

Figure 10) Left thigh scar at six months (April 22, 2008)

4. Schmid MR, Kossmann T, Duewell S. Differentiation of necrotizing fasciitis and cellulitis using MR imaging. AJR Am J Roentgenol 1998;170:615-20.

5. Rao RB, Ely SF, Hoffman RS. Deaths related to liposuction. New Engl J Med 1999;340:1471-5.

6. Jackson R, Bell M. Phagedena: Gangrenous and necrotic ulcerations of skin and subcutaneous tissue. Can Med Assoc J 1982;126:363-8.

7. Swartz M. Cellulitis. N Engl J Med 2004;350:904-12.

8. Hopkins KL, King CP, Bergman G. Gadolinium-DTPA-enhanced magnetic resonance imaging of musculoskeletal infectious processes. Skeletal Radiol 1995;24:325-30.

9. Struk D, Munk P, Lee M, Ho S, Worsley D. Imaging of soft issue infections. Radiol Clin North Am 2001;39:277-301.

10. Chivers QJ, Lindsay RL. The use of early clinical features and laboratory values in the determination of necrotizing fasciitis with associated myonecrosis. Poster Presentation, Canadian Society of Plastic Surgeons Annual Meeting, June 2005, Nanaimo, British Columbia 